\title{
GAIA Level 1 Second Trimester Spontaneous Abortion
}

National Cancer Institute

\section{Source}

National Cancer Institute. GAIA Level 1 Second Trimester Spontaneous Abortion. NCI

Thesaurus. Code C128781.

GAIA Level 1 Second Trimester Spontaneous Abortion is defined by two criteria: first, gestational age is within the pre-defined range for the selected abortion definition as assessed by maternal and/or fetal parameters (Level 1-2) (Brighton Preterm Birth Gestational Age algorithm); second, at least one of the following requirements must be met: a) No visible heartbeat on ultrasound; OR b) Visible expulsion of pregnancy tissues/products of conception on examination of the cervix; OR c) Products of conception found on histopathological evaluation of uterine contents. 